\title{
PROPAGACIÓN IN VITRO DE BAMBÚ CHINO (Dracaena sanderiana $\mathrm{L}$.)
}

\author{
${ }^{\bullet}$ Marcos Daquinta Gradaille, Danay Pacheco Rodríguez, Yariane Lezcano Más y Fernando Sagarra Torrijo \\ Centro de Bioplantas, Universidad de Ciego de Ávila, Carretera a Morón Km. 9, Ciego de Ávila \\ C. P.: 69450,Cuba. ${ }^{\circledR}$ daquinta@bioplantas.cu
}

\begin{abstract}
Resumen
$\mathrm{C}$ Con el objetivo de establecer un protocolo para la propagación in vitro de Bambú chino (Dracaena sanderiana $\mathrm{L}$.), se evaluaron diferentes tiempos de desinfección de las yemas con bicloruro de mercurio ( $\mathrm{Hg}$ $\mathrm{Cl}_{2}$ ) a $0.2 \%(\mathrm{~m} / \mathrm{v})$, distintas condiciones de cultivo para el establecimiento de las yemas, tanto en condiciones de luz y oscuridad, así como diferentes formas de cultivo y manejo de los explantes para la proliferación de los brotes y distintos niveles de AIB para el enraizamiento de los brotes. Se logró realizar el establecimiento in vitro de la Dracaena sanderiana a partir de yemas laterales de estacas de plantas adultas, en medio de cultivo MS (1962) con $1 \mathrm{mg} \mathrm{L}^{-1}$ de BAP en estado semisólido y bajo condiciones de oscuridad. Para la proliferación de brotes, el seccionamiento longitudinal de estos y los sistemas de inmersión permanente, en el medio de cultivo MS (1962) enriquecido con BAP $\left(2 \mathrm{mg} \mathrm{L}^{-1}\right)$ combinado con ANA resulto ser el mejor tratamiento. La aclimatización de los brotes de Dracaena sanderiana se realizó en un sustrato compuesto de zeolita cachaza (1:1) en condiciones de casa de cultivo, con un sistema de riego por microjet
\end{abstract}

Palabras claves: Agavaceae, Inmersión, oscuridad.

\section{Abstract}

$\mathrm{W}$ ith the aim of to found a protocole to in vitro propagation of Chine bamboo (Draceana sanderiana L.), were evaluated different sterilizing time of bud with mercury biclorure $\left(\mathrm{HgCl}_{2}\right) 0.2 \%$ (w/v), two culture condition (light and darkness) to the bud stablishment, different culture way and explants manegement to shoots proliferation and several IBA levelss to shoot rooting. The aclimatization was studied too. The in vitro stablishment of Dracaena sanderiana from lateral buds wase achieved in culture medium MS (1962) semi-solid suplement with $1 \mathrm{mg} \mathrm{L}^{-1} \mathrm{BAP}$ under darkness. To shoot proliferation, the shoots longitudinal cut and permanent immersion systems in culture medium MS (1962) suplement with BAP $\left(2 \mathrm{mg} \mathrm{L}^{-1}\right)$ and ANA was the best tratament. The shoot aclimatization of Dracaena sanderiana was made in zeolita and sugarcane filter substrate $(1: 1)$ in green house condition with system by microjet.

Key words: Agavaceae, Immersion, darkness.

\section{INTRODUCCIÓN}

$\mathrm{D}^{2}$ entro de la familia Agavaceae se encuentran dos géneros que presentan características muy semejantes, Dracaena y Cordyline. Se conocen alrededor de 150 especies de Dracaena y 15 de Cordyline. Sin embargo, apenas 20 ó 30 se cultivan con fines ornamentales (Sánchez de Lorenzo, 2003).

La Dracaena spp, se encontró inicialmente en las Islas Canarias y de allí se trajo a los trópicos americanos, donde se presenta un crecimiento exuberante (Botanical Growers, 2003). Es una planta ornamental conocida por su apariencia y facilidad para crecer en ambientes claros con luz indirectas, pero también puede tolerar poca luz (Clemson, 2003). Se conocen alrededor de 30 especies dentro de este género, entre ellas D. sanderiana, D. marginata, D. deremensis, D. fragrans, D.

Recibido: Octubre, 2009. Aceptado: Enero, 2010.

Publicado como ARTÍCULO en Ciencia y Tecnología 3(1): 7-13. 2010 reflexa, D. godseffiana, D. fragrans, D. warneckii.

Las Dracaenas son multiplicadas por esquejes apicales de tallo o de trozos de $5-8 \mathrm{~cm}$ de longitud, que son enraizados con el uso de reguladores de crecimientos. Posteriormente, los esquejes se colocan en una mezcla de turba y arena tratada con fungicidas. En estas condiciones el enraizamiento se produce al mes de la siembra. También, esta planta se reproduce por semilla. Sin embargo, para que la planta florezca debe someterse a temperatura inferiores a los $12-14^{\circ} \mathrm{C}$ o a un tratamiento con ácido giberélico. Los racimos tardan de 4-6 meses en madurar y la germinación se produce a las 6-8 semanas de la siembra (Infoagro, 2003; Sánchez de Lorenzo, 2003).

Mediante el cultivo in vitro de brotes del tallo se ha logrado establecer protocolos para $D$. marginata "Tricolor" (Chua et al., 1981) y D. fragrans (Vinterhalter et al., 1990; Vinterhalter, 1992). 
Con base en lo anterior la presente investigación tuvo como objetivo: Establecer un protocolo para la propagación in vitro de la Dracaena sanderiana L., que permita en un futuro la comercialización de esta planta.

\section{Materiales y Métodos}

Evaluación de la desinfección de yemas de Bambú chino con diferentes tiempos en bicloruro de mercurio $(0.25 \%)$.

Se utilizaron yemas nodales de plantas seleccionadas de Bambú chino, se procedió a su lavado con detergente comercial y se enjuagaron con abundante agua, en el flujo laminar se realizó la desinfección con Bicloruro de Mercurio al $0.25 \%(\mathrm{~m} / \mathrm{v})$ durante 3, 5 y $7 \mathrm{~min}$.

Se procedió a la extracción de las yemas, las que se implantaron en el medio de cultivo compuesto por sales de Murashige-Skoog (1962) (MS), $1.0 \mathrm{mg} \mathrm{L}^{-1}$ de tiamina, $100 \mathrm{mg} \mathrm{L}^{-1}$ de Mioinositol, $30 \mathrm{~g} \mathrm{~L}^{-1}$ de Sacarosa, $1 \mathrm{mg} \mathrm{L}^{-1}$ BAP y $2.5 \mathrm{~g} \mathrm{~L}^{-1}$ de Gelrite. Los cultivos se incubaron en condiciones de oscuridad, y a los 21 días se evaluaron las yemas contaminadas.

Evaluación de las condiciones de cultivo (luz y oscuridad) en el establecimiento de yemas de Bambú chino.

Se utilizaron yemas latentes del bambú chino proveniente de tallos de la plantas madres desinfectados con bicloruro de mercurio a $0.25 \%(\mathrm{~m} / \mathrm{v})$ durante $5 \mathrm{~min}$. Las yemas se extrajeron y se establecieron en el medio de cultivo descrito en el epígrafe anterior y se incubaron en oscuridad y luz a $37 \mu \mathrm{M} \mathrm{m}^{-2} \mathrm{~s}^{-1}$ con un fotoperíodo de 16 horas de luz y 8 horas de oscuridad. A los 30 días se evaluó el número de yemas brotadas.

Comparación de la técnica de cultivo en la multiplicación de brotes de Bambú chino (Dracaena sanderiana $\mathbf{L}$.).

Se seleccionaron brotes individuales uniformes de $2 \mathrm{~cm}$ de longitud, se inocularon en el medio de cultivo referido anteriormente, pero enriquecido con 2 mg L $\mathrm{L}^{-1}$ BAP y $0.5 \mathrm{mg} \mathrm{L}^{-1}$ de ANA en diferentes formas de cultivo:

a) Medio de cultivo semisólido $2.5 \mathrm{~g} \mathrm{~L}^{-1}$ Gelrite.

b) Medio de cultivo líquido en agitación. Los brotes se colocaron en Erlenmeyer de $300 \mathrm{~mL}$ de capacidad y se mantuvieron en agitador orbital a $120 \mathrm{rpm}$.

c) Medio de cultivo líquido en Sistema de Inmersión Permanente con ventilación forzada. Para ello se cultivaron los brotes en frascos de $300 \mathrm{~mL}$ de capacidad con el medio de cultivo y se colocaron en los estantes de inmersión, recibiendo una inyección de aire cada 3 horas.

d) Medio de cultivo líquido en Sistemas de Inmersión Temporal. Para esto, se colocaron los brotes en sistemas constituidos con frascos de vidrios de $300 \mathrm{~mL}$ de capacidad y se colocaron en los estantes con una frecuencia de inmersión cada 3 horas durante 4 min (resultados no publicados).

En todas las variantes ensayadas se colocó 50 $\mathrm{mL}$ de medio de cultivo por recipiente utilizado. En los tratamientos donde se utilizó medios de cultivo semisólido y líquido en agitación se utilizaron 10 repeticiones, sin embrago en los Sistemas de Inmersión se emplearon tres repeticiones por tratamiento. A los 45 días se evaluó el número de brotes de cultivo y las diferentes formas de cultivo y la presencia o no de brotes hiperhídricos.

\section{Evaluación del manejo de explantes en la multipli- cación de las yemas de Bambú chino (Dracaena san- deriana L.).}

Se utilizaron brotes de bambú chino obtenidos a partir de yemas nodales en medio de establecimiento. Se establecieron dos manejos de los explantes, un grupo de brotes se dejaron como control, no fueron seccionados y el otro fue seccionado longitudinalmente. Ambos tipos de explantes se establecieron en el medio de cultivo referido en el epígrafe anterior, líquido en agitación donde los brotes se colocaron en Erlenmeyer de $300 \mathrm{~mL}$ de capacidad con $50 \mathrm{~mL}$ de medio de cultivo y se mantuvieron en agitador orbital a $120 \mathrm{rpm}$. En el tratamiento con medio de cultivo líquido en sistema de inmersión permanente con ventilación forzosa, se colocaron los brotes en frasco de $300 \mathrm{~mL}$ de capacidad con $50 \mathrm{~mL}$ de medio de cultivo y se colocaron en los estantes de inmersión recibiendo una inyección de aire cada 3 horas. En el tratamiento donde se utilizó medio de cultivo líquido en agitación se utilizaron 10 repeticiones, sin embrago en los Sistemas de Inmersión Permanente se emplearon tres repeticiones por tratamiento. A los 45 días se evaluó el número de brotes emitidos.

\section{Evaluación de diferentes concentraciones de AIB en el enraizamiento de brotes de Bambú chino.}

Se utilizaron brotes individuales de $2-3 \mathrm{~cm}$ de longitud provenientes de la multiplicación en medio de cultivo líquido en agitación. Los brotes se subcultivaron en los siguientes tratamientos: MS $+(0,0.25,0.50$ y 1.0 $\mathrm{mg} \mathrm{L}^{-1}$ Acido IndolButirico).

A las seis semanas se evaluó el número de brotes enraizados, el número de raíces/brotes y el largo de la mayor raíz $(\mathrm{cm})$. 


\section{Resultados y Discusión}

Evaluación de la desinfección de yemas de Bambú chino con diferentes tiempos en bicloruro de Mercurio $(0.25 \%)$.

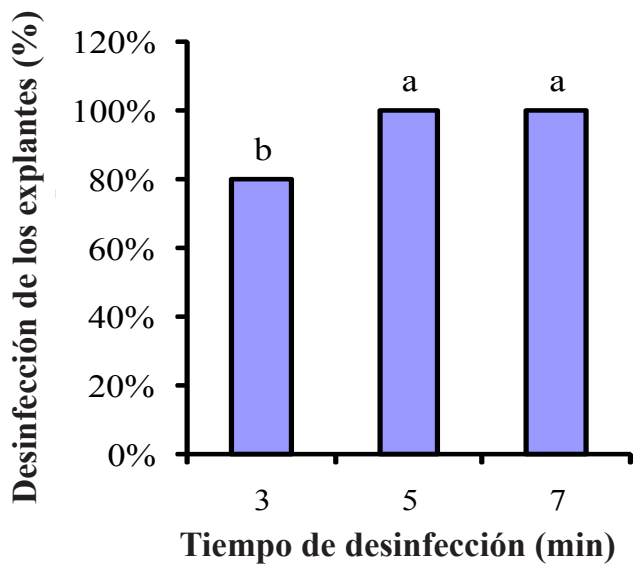

Figura 1. Efecto de la desinfeccion con Bicloruro de Mercurio $(0.25 \%)$ en las yemas de Dracaena sanderiana durante los diferentes tiempos, a los 21 días de cultivo. Medias con letras desiguales difieren entre sí para un valor de $\mathbf{p}<0.05$ (KruskalWallis, Student-Newman-Keuls, es=0.031)

$\mathrm{E}^{\mathrm{n}}$ n la Figura 1 se puede observar que a medida que se aumenta el tiempo de desinfección con Bicloruro de Mercurio a $0.25 \%(\mathrm{~m} / \mathrm{v})$, se logra un aumento del porcentaje de desinfección de los explantes. Con el tiempo de desinfección de 5 y 7 min se observo un 100\% de explante sin contaminación, con diferencia significativa con $3 \mathrm{~min}$, pero no se encontró ninguna diferencia entre 5 y 7 min.

Beruto et al. (2004), lograron la desinfección de los explantes de Paeonia suffruticosa con una solución de Bicloruro de Mercurio al 0.5\% (m/v) durante 3 min. En el manejo de la desinfección de los explantes se puede usar el producto concentrado durante poco tiempo como es el caso de Beruto et al. (2004), o el producto menos concentrado con tiempos de exposición del explante mayor, como se empleo en el presente trabajo.

Por otra parte, Bhatt y Dhan (2004), lograron la desinfección de los segmentos de brotes de Myrica esculenta con Bicloruro de Mercurio al $0.1 \%(\mathrm{~m} / \mathrm{v})$ durante $10 \mathrm{~min}$, con este tratamiento de desinfección estos autores alcanzaron más de $60 \%$ de establecimiento en los explantes.

Evaluación de las condiciones de cultivo (luz y oscuridad) en el establecimiento de yemas de Bambú chino (Dracaena sanderiana $\mathrm{L}_{\text {.). }}$.
En la Figura 2, en condiciones de oscuridad se logró la mayor brotación de las yemas a las dos semanas de cultivo, esta repuesta se mantuvo en el cultivo sin variar durante todo el periodo evaluado. Sin embargo, la brotación de las yemas establecidas en condiciones de iluminación se comportó por debajo de la repuesta obtenida bajo condiciones de oscuridad, se encontró diferencia estadística entre ambas condiciones de cultivo. Aunque el porcentaje de repuesta se incremento a partir de la segunda semana de cultivo en condiciones de luz, se mantuvo por debajo de los niveles alcanzado en la oscuridad. Al final del período evaluado, a las cuatros semanas sólo se alcanzo un $28.5 \%$ de yemas brotadas en condiciones de luz.

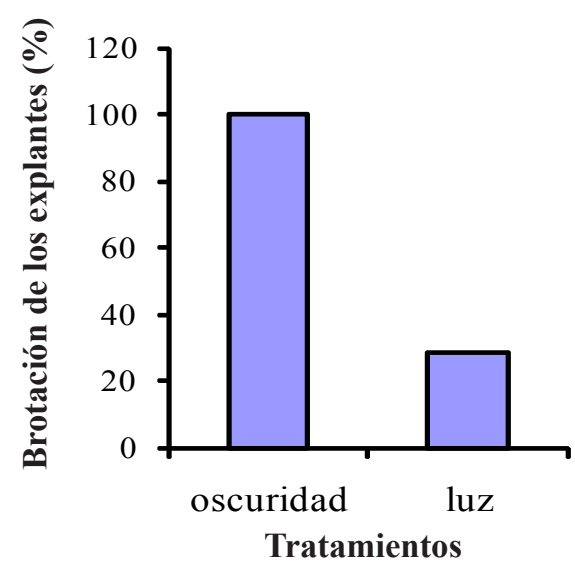

Figura 2. Efecto de las condiciones de iluminacion en el establecimiento de yemas de Bambú chino, a los 30 días de cultivo. Las medias presentaron diferencias significativas entre sí para un grado de significación de $\mathbf{p}<\mathbf{0 . 0 5}$ (Mann-Whitney, *es= 0.12)

Aliyu (2005) señalo que el cultivo in vitro en la oscuridad del Marañón (Anacardium occidentale) tuvo un efecto positivo sobre la elongación de los brotes.

La etiolación de ramas antes de escindir los ápices ha facilitado en gran medida el establecimiento in vitro, y la subsiguiente multiplicación, de tejidos procedentes de árboles maduros de Castanea y Quercus. Presumiblemente un fenómeno de esta naturaleza es debido a que la etiolación reduce la edad fisiológica señalan Ballester et al. (1989). La etiolación continúan planteando estos autores ha demostrado ser útil para facilitar el enraizaimento in vivo e in vitro, como se pudo observar en este trabajo, al establecer las yemas en condiciones de oscuridad. Es conocido que la etiolación causado por la oscuridad o baja iluminación, puede producir la ruptura de la dormancía de las yemas. 
Choi et al. (2001) señalan que la incubación durante cuatro o cinco semanas en la oscuridad fue la condición más efectiva para la exitosa regeneración de brotes en dos cultivares de Diospyros kaki, siendo esencial para la formación de brotes adventicias en el cv. Fuyu. Kirdmanee et al. (2004) lograron cultivar yemas de jengibre en el medio de cultivo MS (1962) en condiciones de oscuridad por un mes.

Comparación de la técnica de cultivo en la multiplicación de brotes de Bambú chino (Dracena sanderiana $\mathrm{L}$.).

Como se muestra en la Figura 3, la mayor respuesta en el número de brotes se obtuvo en el medio de cultivo líquido en agitación o en los sistemas de inmersión permanente. Los mejores resultados se alcanzaron en las formas de cultivo donde los explantes siempre estuvieron siempre en contacto directo con el medio de cultivo, es decir en los medios de cultivo líquido en agitación y en los Sistemas de Inmersión Permanente y no a través de un gel como sucede en el medio de cultivo semi-sólido. Era de esperar que estas formas de cultivo produjeran hiperhidricidad en los brotes, sin embargo, el Bambú chino parece ser una planta que está adaptada para ser cultivada en agua, por lo que no se presentaron brotes hiperhídricos.

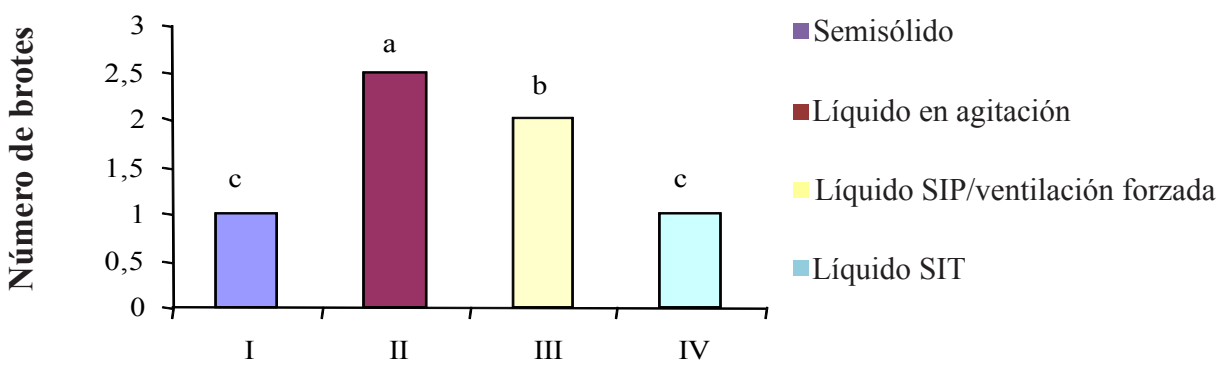

Diferentes técnicas de cultivo en la multiplicación

Figura 3. Efecto del sistema de cultivo en la multiplicación de brotes in vitro de Dracaena sanderiana $\mathrm{L}$., a los 45 días de cultivo. Medias con letras desiguales difieren entre sí para un valor de $\mathbf{p}<\mathbf{0 . 0 5}$. (Kruskal-Wallis, Student- Newman- Keuls, es=0.09)

Utilizando estos sistemas de inmersión temporal en la propagación in vitro de clones de Caladium $x$ hortulanum, con frecuencia de inmersión similar logró incrementar hasta seis veces el número de brotes en comparación con el medio semi-sólido, así como reducir el ciclo de multiplicación. Estos resultados indican que para la propagación axilar del Caladium, el sistema de inmersión temporal es superior al cultivo en medio semi-sólido (Daquinta et al., 2007). En general, los sistemas de inmersión temporal han tenido una aplicación favorable para la propagación de la mayoría de las especies en que han sido ensayados, al aumentar la tasa de multiplicación y calidad de los brotes de Bromelias, Gladiolos y Zantedeschia.(Daquinta et al., 2001, Ruffoni et al., 2008, Sánchez et al., 2009)

Entre sus principales ventajas se encuentran: que permiten un suministro eficiente de los nutrientes en el medio líquido así como la transferencia de oxígeno, reducción de los cortes por fuerzas hidrodinámicas, evitan la hiperhidricidad, mejoran la calidad de las plan- tas previo a la aclimatización y además la semi-automatización del proceso reduce los costos de producción (Etienne y Berthouly, 2002).

Saare-Surminski et al. (2008) emplearon los sistemas de inmersión temporal para la multiplicación in vitro de Gentiana, la Inmersión temporal indujo un mayor número de brotes e incrementó la calidad de los mismos para ser trasplantados a invernaderos. Este sistema fue utilizado con éxito para la multiplicación de brotes de Phalaenopsis hibridas (Pisowotzki el at., 2008). A pesar de que estos sistemas han sido aplicados en una gran variedad de especies de plantas, no se han encontrado referencias de su aplicación en la propagación de especies de la familia Agavaceae. Es por ello, que el empleo de las técnicas de inmersión temporal, para la micropropagación de especies de Dracaenas resulta una alternativa interesante para incrementar las tasas de multiplicación, la calidad de las plantas y reducir los costos de producción. 
Evaluación del manejo de explantes en la multiplicación de las yemas de Bambú chino (Dracaena sanderiana $\mathbf{L}$.)

En el Cuadro 1, se presenta el comportamiento del número de brotes obtenidos en los explantes seccionados y no seccionados, en las dos mejores formas de cultivo obtenidas en el experimento anterior (medio de cultivo líquido en agitación y en Sistemas de Inmersión Permanente). Siempre que se realizó el seccionamiento de los brotes, se logró duplicar el número de brotes, tanto en el medio de cultivo líquido en agitación, así como el medio de cultivo líquido en los sistemas de inmersión permanente, con diferencias estadísticas con respecto a los brotes sin seccionar.

Aunque desde hace varios décadas la micro- propagación de bananas se ha realizado mediante la decapitación del pseudotallo de los brotes, recientemente Madhulatha et al. (2004) utilizó ápices de brotes decapitados del $c v$ Nendran para evaluar los pulsos con citoquininas durante varios tiempos. Además de decapitar los brotes de bananos y plátanos para la micropropagación a nivel comercial, estos brotes son seccionados longitudinalmente en dos o cuatro secciones en dependencia del tamaño del cormo.

Parthanturarug et al. (2003) al estudiar el tipo de explante, lograron los mejores resultados en yemas terminales de Curcuma longa decapitados y divididos longitudinalmente en cuatro partes igual. Estos investigadores demostraron que la yema terminal de C. longa puede ser dividida en cuatro partes para ser usada como explante en la propagación in vitro de esta planta.

Cuadro 1. Efecto del manejo de los explantes en la multiplicación de los brotes de Dracaena sanderiana L. (Bambú chino), a los 45 días de cultivo

\begin{tabular}{lcccc}
\hline \multicolumn{1}{c}{$\begin{array}{c}\text { Manejo de } \\
\text { los explantes }\end{array}$} & $\begin{array}{c}\text { Medio líquido } \\
\text { en agitación }\end{array}$ & $\begin{array}{c}\text { Medio líquido } \\
\text { en SIP }\end{array}$ \\
\hline Brotes sin seccionar & 2.50 & $\mathrm{c}$ & 2.00 & $\mathrm{c}$ \\
Brotes seccionados & 5.00 & $\mathrm{~b}$ & 7.00 & $\mathrm{a}$ \\
\hline
\end{tabular}

Medias con letras desiguales difieren significativamente entre sí para un valor de $\mathrm{p}<0.05$ (Kruskal-Wallis, Student-Newman-Keuls, es=0.36). SIP-Sistema de Inmersión Permanente

Evaluación de diferentes concentraciones de AIB en el enraizamiento de brotes de Bambú chino (Dracaena sanderiana $\mathrm{L}$.)

Las concentraciones evaluadas de esta auxina, no presentaron diferencias estadísticas, pero sí con res- pecto al testigo (Figura 4), donde se logró sólo el 60\% de los brotes enraizados. Por otra parte, el comportamiento del número de raíces y largo de la raíz mayor se muestran en el Cuadro 2, donde se encontró un incremento en el número de raíces formadas con el aumento de las concentraciones de la auxina (AIB).

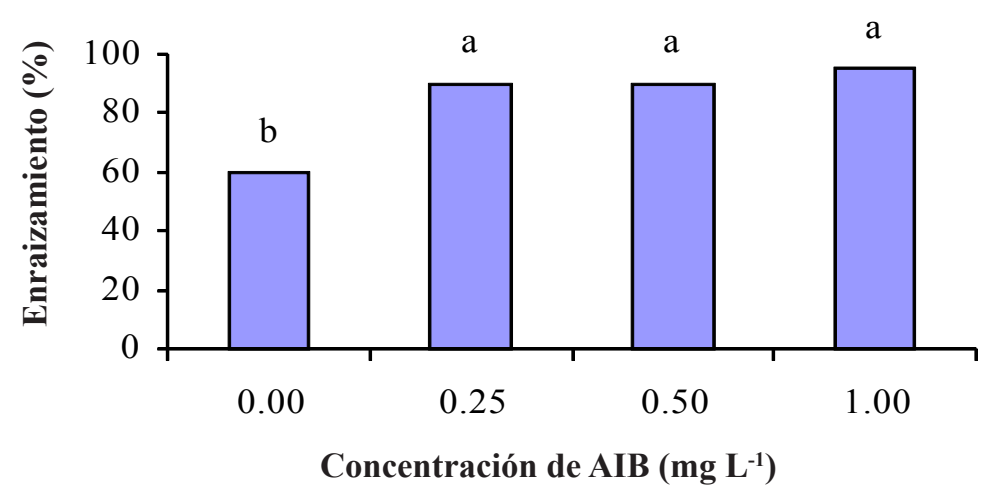

Figura 4. Efecto de la auxina (AIB) sobre el enraizamiento de los brotes de Bambú chino (Dracaena sanderiana L.), a los 45 días de cultivo. Medias con letras desiguales difieren entre sí para un valor de $\mathbf{p}<0.05$ (Kruskal-Wallis, Student-Newman-Keuls, es=0.035) 
Daquinta et al.

Cuadro 2. Influencia de diferentes concentraciones de AIB sobre el número de raíces y largo de la raíz mayor de las plantas de Bambú chino (Dracaena sanderiana $L$.), a los 45 días de cultivo

\begin{tabular}{cccc}
\hline $\begin{array}{c}\text { Concentración de } \\
\text { AIB }\left(\mathbf{m g ~ L}^{-1}\right)\end{array}$ & $\begin{array}{c}\text { Número de } \\
\text { raíces }\end{array}$ & $\begin{array}{c}\text { Largo de la raíz } \\
\text { mayor }(\mathbf{c m})\end{array}$ \\
\hline $\mathbf{0 . 0 0}$ & 2.00 & $\mathrm{~b}$ & 7.50 \\
$\mathbf{0 . 2 5}$ & 5.10 & $\mathrm{a}$ & 8.00 \\
$\mathbf{0 . 5 0}$ & 6.20 & $\mathrm{a}$ & 7.60 \\
$\mathbf{1 . 0 0}$ & 7.40 & $\mathrm{a}$ & 6.40 \\
$\mathbf{e s}$ & 0.56 & 0.37 \\
\hline Significación & $*$ & $\mathrm{NS}$ \\
\hline
\end{tabular}

Medias con letras desiguales en una misma columna difieren significativamente entre sí para un valor de $\mathrm{p}<0.05$ (Kruskal-Wallis, Student-Newman-Keuls, es=0.465)

A pesar de que Blanco et al. (2004) lograron el enraizamiento de los brotes de Dracaena deremensis sin reguladores del crecimiento en el medio de cultivo, en la especie en estudio en el presente trabajo fue necesario la presencia de una auxina. Junaid et al. (2008) lograron el enraizamineto de los brotes de Dracaena sanderiana en medio de cultivo enriquecido con AIB; con $1.5 \mathrm{mg}$ $\mathrm{L}^{-1}$ de esta auxina se logró un marcado incremento en el enraizamiento de los brotes. Por otra parte Nourissier y Monteuuis (2008), trabajaron con híbridos de Eucaliptos, de las auxinas evaluadas, el AIB fue la que mejor comportamiento presentó en cuanto al porcentaje de enraizamiento, número de raíces y largo de estas.

En Cordia trichotoma, Mantovani et al. (2001) lograron el mejor enraizamiento de los brotes de esta especie con $0.5 \mathrm{mg} \mathrm{L}^{-1}$ de AIB en el medio de cultivo, combinado con carbón activado.

\section{Conclusiones}

$\mathrm{E}$ n este trabajo la mejor desinfección de los explantes ¿de Bambú chino (Dracaena sanderiana) se logró con el tratamiento de bicloruro de mercurio a $0.25 \%$ $(\mathrm{m} / \mathrm{v})$ durante $5 \mathrm{~min}$. Por otra parte la dormancia de las yemas se eliminó al incubar los explantes en la oscuridad, lo cual permitió la brotación al 100\% de las mismas. Las mejores condiciones para la multiplicación de los brotes de Bambú chino (Dracaena sanderiana) se lograron al seleccionar los brotes longitudinalmente y cultivados en medio de cultivo líquido en sistemas de inmersión permanente. Se logró más del $90 \%$ de enraizamiento de los brotes de Bambú chino (Dracaena sanderiana) con el uso de AIB en el medio de cultivo y la aclimatización en sustrato de zeolita, posibilito alcanzar el $100 \%$ de supervivencia de los brotes.

\section{Literatura Citada}

Aliyu, O. M. 2005. Application of tissue culture to cashew (Anacardium occidentale L.) breeding: A appraisal. African Journal of Biotechnology 4(13): 1485-1489.

Ballester, A., M. C. Sanchez, A. M. Vieetez. 1989. Etiolation as a pretreatment of in vitro establishment and multiplication of mature Chesnut. Physiol Plant. 77: 395-400.

Beruto, M., L. Lanteri, C. Portogallo. (2004) Micropropagation of tree peony (Paeonia suffruticosa) Plant Cell, Tissue and Organ Culture 79:249-255.

Blanco, M., R. Valverde, L. Gomez. 2004. Micropropagación de Dracaena deremensis. Agronomía Costarricense 28 (1): 7-15.

Botanical Growers. 2003. Tropical Dracaena plants. htpp://botanicalgrowers.com.

Bhatt, I. D., U. Dhar. 2004. Factors controlling micropropagation of Myrica esculenta bunch. - Ham. Ex D Don: a high value wild edible of Kumaun Himalaya. African Journal of Biotechnology, 3(10): 534-540.

Clemson extension. 2003. Dracaena. http//hgic.clemson.edu/factsheets/HGICI 504.htm

Cha-um, S., N. M. Tuan, K. Phummakong, C. Kirdmanee. 2005. The ex vitro survival and growth of Ginger (Zingiber officinale. Roscoe.) Influence by in vitro acclimatization under high relative humidity and $\mathrm{CO}_{2}$ enrichment conditions. Asian Journal of Plant Sciences, 4 (2): 109-116.

Chein, X., D. Chakrabarty, E. J. Hahn, K. Y. Paek. 2003. A simple method for mass production of potato microtubers using a bioreactor system. Current Science 84 (8): 1129-1132 
Choi, J. Y., H. J. Kim, C. H. Lee, J. M. Bae, Y. S. Chung, J. S. Shin, N. I. Hyung. 2001. Efficient and simple plant regeneration via organogenesis from leaf segment cultures of Persimmon (Diospyros kaki. Thumb). In vitro Cell. Dev. Biol- Plant. 37: 274279.

Chua, B., J. Kunisaki, N. Sagaway. 1981. In vitro propagation of Dracaena marginata "Tricolor". HortScience 16(4): 494.

Daquinta, M., P. Espinosa, M. Escalona, R. Rodríguez, M. Guerra. 2001. Bromeliad micropropagation in Temporary Inmersion System. Journal of the Bromeliad Society.51 (2): 80-85.

Daquinta, M., O. Mosqueda, M. Gonzalez, R. Benega, J. Teixeira. 2007. Shoot proliferation of Caladium $\mathrm{x}$ hortulanum in Temporary Immersion Systems. Floriculture and Ornamental Biotechnology 1(1): $70-72$.

Etienne, H., M. Berthouly. 2002. Temporary immersion systems in plant micropropagation. Plant Cell, Tissue and Organ Culture. 69:215-231.

Infoagro. 2003. Cordiline http//www.infoagro.com/flores/plantas_ornamentales/cordiline-asp

Junaid, A., A. Mujib, M. P. Sharma. 2008. Effect of growth regulators and ethylmethane sulphonate on growth, and chlorophyll, sugar and proline contents in Dracaena sanderiana cultured in vitro. Biologia Plantarum. 52(3): 569-572

Kirdmanee, C., K. Mosaleeyanon, M. Tanticharoen. 2004. A novel approach of bacteria-free rhizome production of ginger through biotechnology. Acta Horticultrae 629: 20-23

Madhulatha, P., M. Anbalagan, S. Jayachandran, N. Sakthivel. 2004. Influence of liquid pulse treatment with growth regulators on in vitro propagation of banana (Musa spp. AAA). Plant Cell, Tissue and Organ Culture. 76: 189-191.

Mantovani, N. C., E. T. Henz Franco, S. Vestena. 2001. Regeneracao in vitro de Louro-Pardo (Cordia trichotoma (Velluzo) Arrabida ex Steudel). Ciencia Forestal, Santa María (Brasil) 11(2): 93-101
Nourissier, S., O. Monteuuis. 2008. In vitro rooting of two Eucalyptus urophylla x Eucalyptus grandis mature clones. In vitro Cell. Dev. Biol. Plant. 44: 263-272

Parthanturarug, S., N. Soonthorncharennon, W. Chuakul, Y. Phaidee, P. Saralamp. 2003. High-frecuency shoot multipolicaction in Curcuma longa L. using thidiazuron. Plant Cell Reports. 21: 1054-1059

Pisowotzki, C., K. Saare-Surminski, R. Lieberei. 2008. Micropropagation of Phalaenopsis-hybrids in Temporary Immersion System (TIS). Effect of exudated phenolic substances on plant development. Propagation of Ornamental Plants. 8(1): 221-223

Ruffoni, B., M. Pamato, A. Giovannini, M. Brea. 2008. Gladiolus micropropagation in Temporary Immersion System. Propagation of Ornamental Plants. 8(2): 102-104.

Saare-Surminski, K., C. Pisowotzki, R. Lieberei. 2008. Shoot propagation of ornamental Gentian in a Temporary Immersion System- Effect of culture parameters on plant quality. Propagation of Ornamental Plants. 8(4): 210-214

Sánchez de Lorenzo, J. M. 2003. Las Dracaenas. htpp:// www.arbolesornamentales.com/Dracaenas.htm.

Sánchez, J., M. Daquinta, I. Capote, J. Teixeira, B. Chadwick. 2009. Frequency of Immersion and Paclobutrazol Application Affect the Propagation of Zantedeschia sp. Var. 'Treasure' Shoots in a Temporary Immersion System. Floriculture and Ornamental Biotechnology 3(1): 46-48

Vinterhalter, D., D. Grubisic, B. Vinterhalter, R. Konjevic. 1990. Light-control root elongation in in vitro cultures of Dracaena fragrans Ker-Gawl. Plant Cell, Tissue and Organ Culture 22: 1-6. 